\title{
Family therapy with Eastern European immigrants: recommendations for practice
}

\author{
Mihaela Robila \\ CUNY Queens College \\ Jonathan G. Sandberg \\ Brigham Young University - Provo, jonathan_sandberg@byu.edu
}

Follow this and additional works at: https://scholarsarchive.byu.edu/facpub

Part of the Other Social and Behavioral Sciences Commons

\section{Original Publication Citation}

Robila, M. \& Sandberg, J. (2011). Family Therapy with Eastern European Immigrants:

Recommendations for Practice. International Journal of Migration, Health and Social Care 7(4), 182- 196.

\section{BYU ScholarsArchive Citation}

Robila, Mihaela and Sandberg, Jonathan G., "Family therapy with Eastern European immigrants: recommendations for practice" (2011). Faculty Publications. 4070.

https://scholarsarchive.byu.edu/facpub/4070 


\title{
Family therapy with Eastern European immigrants: recommendations for practice
}

\author{
Mihaela Robila and Jonathan Sandberg
}

\author{
Mihaela Robila is an \\ Associate Professor of \\ Family Studies at Queens \\ College, City University of \\ New York, Flushing, \\ New York, USA. \\ Jonathan Sandberg is an \\ Associate Professor of \\ Marriage and Family \\ Therapy at Brigham Young \\ University, Provo, Utah, \\ USA.
}

\begin{abstract}
Purpose - The increased number of Eastern European immigrants provides many opportunities to work with these immigrants and issues related to immigration. The purpose of this article is to examine Eastern European immigrants' adaptation patterns and provide recommendations for family therapy working with the group.
\end{abstract}

Design/methodology/approach - Semi-structured interviews were conducted with 120 Eastern European immigrants. Data analysis was conducted using constant comparisons.

Findings - Common immigration experiences illustrating the need for services have been identified, along with barriers that might prevent the use of social services. The results indicate similarities and differences among the different groups regarding their immigration experience and adaptation to the host society.

Originality/value - Recommendations for overcoming the service-use barriers and conducting family therapy with these immigrants are provided.

Keywords Family therapy, Eastern European immigrants, Immigrants, Social services

Paper type Research paper

\section{Introduction}

With 38.4 million migrants representing 13.5 per cent of its population, the USA is the country with the highest number of international migrants (an increase from 19.8 million in 1990, representing 7.9 per cent of population) (International Organization on Migration, 2007). During the communist regime (1945-1990), immigration from Eastern Europe was limited, but the number of immigrants from this region increased greatly in the last two decades. Currently, about 10 per cent of legal immigrants to the USA are from Eastern Europe, representing about 70 per cent of all contemporary European immigrants coming to the USA (US Department of Homeland Security, 2008). The number also increased in Western Europe as well. For example, in the UK, Eastern European immigration accounts for about one third of net foreign immigration since the European Union (EU) enlargement in 2004 when EU included the Czech Republic, Estonia, Hungary, Latvia, Lithuania, Slovakia, Slovenia and Poland (in 2007 another enlargement occurred when Romania and Bulgaria also joined EU) (Migration Watch UK, 2009). Although research on Asian and Hispanic immigrants has increased greatly (Leon Siantz, 1997; Zeng and Xie, 2004; Yip and Fuligni, 2002), the literature on Eastern European immigrants is still limited (Robila, 2004, 2009). The purpose of this article is to examine the challenges of Eastern European immigrants and their need for social services as they try to adapt to life in the USA, the barriers encountered in using these services, and the strategies to overcome them. Recommendations for conducting family therapy with these groups are also provided.

\section{Review of literature: Eastern European immigration issues}

Immigration brings complex opportunities and challenges at the family level (Alba and Nee, 2003; Massey et al., 1998; Portes and Hao, 2002). Many immigrants find greater opportunities
The research presented in this paper was supported by grants Research and Experimentation and from CUNY Research Foundation to the first author. The authors are grateful to all participants in the study. 
for economic resources than in the native country, as well as chances to develop professional skills. Among the challenges are understanding and adapting to the new social and economic system, and the lack of the social support structure (e.g. family members, friends) (Robila, 2008; Rumbaut, 1994). Dealing successfully with these challenges is a major task in the process of adapting to a new culture. For example, the lack of social and family resources might place immigrants at increased vulnerability and risk for depression and anxiety, due to the decreased coping options in a new land. Different social services are in place to provide support to different immigrant groups (Wang, 1994). However, the services designed specifically for Eastern European groups are extremely limited. Unfortunately, even where culture specific resources exist, many Eastern European groups view mental health or social service utilization as a sign of weakness (Young et al., 1987).

\section{Need for social services: challenges of immigration}

Eastern European immigrants like other immigrant groups have been confronted with different challenges while adapting to life in the USA. Some challenges documented as part of the immigration experience have been: economic difficulties, learning the language of the host country, continuing education credentials, and the timing of migration or family conflicts (Buchwald et al., 1993; Krupinski et al., 1973).

\section{Financial challenges}

Immigrants are more likely than the native population to encounter economic difficulties such as unemployment, due to the fact that some of their capabilities such as professional or language skills might not be transferable in the new society. The length of unemployment and the time spent looking for jobs impact immigrants' economic attainment considerably. As a result, many immigrants' earnings are lower than natives, and thus many live in poverty. For example, in 2003, 16.1 per cent of foreign-born people were living below the poverty line (compared with 11 per cent of natives) (Schmidley, 2003). Even controlling for family structure, immigrant families are generally worse off. Previous data indicate that "two-parent immigrant families (44 per cent) are twice as likely as the two-parent native families (22 per cent) to have low incomes" (Urban Institute, 2003, p. 16). In single parent families, 72 per cent of immigrant parents are poor, while 61 per cent of native parents report low income.

\section{Educational challenges}

A study of Eastern European immigrants using the 2000 Census data indicates that there are wide differences in their educational level (Robila, 2007). While in some groups high percentages are well educated (graduate/professional degree) such as those from Bulgaria (32.8 per cent), Russia (27.8 per cent), Romania (20.5 per cent), Belarus (20.3 per cent), and Latvia (20.1 per cent); for others the percentages are considerably lower: Bosnia/ Herzegovina (4.4 per cent), Macedonia (5.4 per cent), and Yugoslavia (8.2 per cent). Although on average, the education level of Eastern European immigrants is higher than Latino immigrants (e.g. only 4.2 per cent have a Bachelor's degree or higher), the large variation in educational levels among Eastern European immigrants calls for specific attention to their country of origin conditions as well as their arrival time. This could be due to the fact that majority of people coming from the former Yugoslavia were coming during or after the war as refugees, while those coming from the other countries are coming on employment visas (which require higher education diplomas) based on US needs (Robila, 2007).

Because of different requirements (e.g. different types of courses, different number of credits), different levels of technology, and different systems of economy, immigrants' education may be greatly discounted in the USA. In addition, upon arrival in the USA, immigrants have to translate their educational credentials into English. Many times, the translation does not reflect the true qualifications, contributing to the discounting of their degrees (Massey et al., 1998; Hao and Ozgur, 2004).

VOL. 7 NO. 42011 INTERNATIONAL JOURNAL OF MIGRATION, HEALTH AND SOCIAL CARE $\mid$ PAGE 183 


\section{Family challenges}

Immigration has a profound impact on families at the marital dyad level as well as the parent-child level. In many cases, families immigrate in stages, leaving some family members in their homeland. This pattern places strain on families as they work to manage long distance relationships (Portes and Rumbaut, 1996). Other factors pertaining to immigration that could impact marital relations are finding employment or struggling with economic stress, conflicts regarding different cultural perspectives between the country of origin and the new environment regarding marital/gender roles or parenting (Falicov, 1988; Falicov and Karrer, 1984; Fuligni, 2003).

Immigrant parents are usually concerned about the transmission of ethnic/cultural identity to their children, supporting them in their adaptation process, maintaining a balance between their own childrearing views and the ones belonging to the new environment (Fuligni, 2003; Parra-Cardona et al., 2008; Portes and Rumbaut, 2001; Rumbaut, 1994). Ethnic identity is defined as group membership, as an aspect of one's social identity, and it can be understood as the subjective sense of belonging to an ethnic group and the feelings and attitudes that accompany this sense of group membership (Phinney et al., 2001). As smaller groups, maintaining ethnic identity is particularly important for Eastern European immigrants (Bakalian, 1993; Manoogian et al., 2007; Okoomian, 2002; Papazian, 2000).

\section{Barriers in using social services}

Previous literature on Eastern European indicate that families are relatively private, solving problems, asking and providing support occurring generally within the family system (Bodrug-Lungu, 2004; Robila, 2004). Similar with other cultural groups (Mittal and Hardy, 2005; Wang, 1994), many Eastern Europeans have cultural scripts about not sharing one's problems and concerns with outsiders. In addition, soliciting outside support is associated with stigma, particularly a sign of weakness. Because in many countries of origin Eastern Europeans do not have the benefit of organized social service, when they migrate to other countries they bring with them stereotypes and even resistance towards asking for and receiving professional support. A third factor is the lack of culturally specific programs, especially for smaller immigrant groups, which also could be a barrier in Eastern Europeans' level of comfort in accessing these services. Finally, a fourth factor might be the lack of trust in outsiders, due to the fear, during the communist time, of government interference in family matters.

\section{Strategies in conducting family therapy with immigrants}

Basic research on mental health issues for Eastern European immigrants is very limited. Most research is conducted with refugees. For example, a study conducted with 47 Hungarians, Romanians, Czechoslovakians, Poles, and Gypsies (90 per cent of them were refugees) in the USA referred to a refugee counseling service indicated that majority of them had poor to fair English skills, less than half were employed, 26 per cent had a previous mental health problems and/or marital/family problems (Buchwald et al., 1993). In survey research of Eastern European refugees living in the USA, researchers have found depression, major fears, and anxieties; however, this study pre-dates the large-scale immigration of the last 20 years (Young et al., 1987). These mental health challenges were also noted in earlier studies among Eastern European refugees and immigrants seeking help for mental health problems, with those likely to be seen in clinical settings being young, often unmarried, frequently unemployed, having low educational attainment and inadequate English skills (Krupinski et al., 1973). Despite the frequency of mental health problems reported in Eastern Europeans refugees and immigrants, the provision of mental health care seems to be insufficient and is likely underutilized (Young et al., 1987). Unfortunately, much of this research is outdated and does not address issues important to current refugees and immigrants.

Working with immigrants requires culturally specific strategies. A culturally sensitive treatment is defined as a treatment mode built on a set of therapeutic assumptions that complements patient's basic value structure (Szapocznik et al., 1978; Coatsworth et al., 2005). 
Besides, addressing the presenting symptoms, the therapist would also need to consider the context of the immigration and its impact on the clients (Levenbach and Lewak, 1995). There is a relatively rich literature on issues related to conducting therapy or counseling with Asian and Hispanic immigrants (Berg and Jaya, 2007; Kinzie et al., 1998; Parra-Cardona et al., 2008). The literature on family therapy or counseling with Eastern European immigrants is limited. The book Ethnicity and Family Therapy by McGoldrick et al. (2005), includes a few chapters on Eastern European families, more specifically on Czech and Slovak families (Krestan and Gazarik, 2005), Hungarian (Laszoffy, 2005), Polish (Folwarski and Smolinski, 2005), and Russian (Newhouse, 2005). For example, in her work with Hungarian families, Laszoffy (2005) indicated that her clients presented openness but also guardedness, which is consistent with the ambivalence towards outsiders. This is similar with the "family secrets" mentioned by Newhouse (2005) in his work with Russian immigrants and the importance of keeping them within the family. These aspects might interfere with the client's openness in discussing family matters with outsiders. Another important issue is the awareness of the wide diversity of cultures in Eastern Europe. For example, even if Czechoslovakia was one country for a long period of time, Czechs and Slovaks have distinct identities, speaking their own language (Czech and Slovak), even if they are similar (Krestan and Gazarik, 2005). The purpose of this study is to present an overview on Eastern European immigrants' challenges and needs for services during their adaptation to the USA, to identify some of the barriers that interfere with using these services, and develop a set of strategies and recommendations to be used while working with them.

\section{Methods}

\section{Sample and procedure}

Semi-structured audio-taped cultural interviews were conducted with 120 Eastern European immigrants (40 Armenian, 40 Romanian, and 40 Russian). Flyers announcing the study were posted in educational settings, community and religious centers (e.g. churches, temples) specific to the three cultural groups. The flyers, as well as the consent form and the interview questions, were written in English and were also translated in each of the three native languages. The interviews were conducted in the language preferred by the respondents. The research team included native speakers of the three languages used by the participants.

Eastern European immigrants were defined as people who were born in Eastern Europe and who now live in the USA. Respondents participated in an approximately one-hour audio-taped semi-structured face-to-face interview. The three immigrant groups had similar demographic characteristics. Armenian immigrants ( 23 women and 17 men) were between 18 and 77 years of age $(M=32)$. They had lived in the USA between four and 29 years $(M=12)$. The study also included 23 Russian immigrant women and 27 men ranging in age from 13 to $64(M=35)$. These Russian immigrants had lived in the USA between one and 20 years $(M=12)$. The Romanian immigrant group consisted of 20 women and 20 men between 24 and 65 years old $(M=39)$ who had lived in the USA between one and 29 years $(M=10)$.

The interview questionnaire addressed issues such as ethnic identity, reasons for immigration, obstacles encountered as immigrants, marital and parenting relations, strategies used to overcome obstacles, social support, and adaptation to the US Questions such as, "What would you change in your life? What are the main things that bother you? What would you like to keep the way it is?" "How do you feel about yourself? Do you feel that you have adapted to the new host country?" highlight the effort to understand the key issues of immigration. The main purpose of the interviews was to learn more about the family context and immigration experiences.

\section{Data analysis}

The interviews were transcribed (and translated when necessary) and checked for accuracy. During the transcription process the lead author wrote memos describing voice expression, emotion, and participant reaction to the content. The research team included 
three researchers who participated in data collection, transcriptions and data analysis. The team collaborated on patterns and themes that emerged both in individual interviews and across all transcripts.

The analytical method used was the constant comparative method (Strauss and Corbin, 1990). Open coding techniques from grounded theory methodology were used to compare observations and to organize participants' comments according to similar or contrasting themes (Strauss and Corbin, 1990). Additionally, a "check-coding" process was used to clarify definitions and enhance inter-coder agreement on the developed themes. In this process, the research team members discussed individual impressions until a consensus was achieved. These codes were subsequently combined, collapsed and/or discarded as a classification system for the emerging themes was developed. As coding of the interviews proceeded, incidents and phenomena were compared for similarities and differences. The "naming" of similar phenomena or coding helped "to label, separate, compile, and organize data" (Charmaz, 1983, p. 111). This was followed by a process of incident conceptualization and grouping of similarities. "Concepts [became] the basic unit of analysis" (Strauss and Corbin, 1990, p. 67). After the open coding process, the axial coding process took place as categories were related to their subcategories. At this stage, the research team members reread the codes and compared existing groupings to identify similarities and differences. Certain codes were combined and those lacking support from the data were omitted. The next stage was to group the codes into higher-level clusters called categories. Selective coding, which is the process by which all categories are unified around a core category, represented the last stage of coding.

\section{Results}

The goal of this study was to identify and describe the challenges experienced by Eastern European immigrants as they try to adjust to life in the USA and to identify social services needs. In addition to identifying these needs, one purpose of the study is to identify barriers to using these services and potential strategies to overcome them. The challenges of migration have been organized around three major themes: issues related directly to migration, the impact of migration on families (marital relation and parenting) and issues related to adaptation. The following paragraphs highlight the themes that emerged from the data. In addition, illustrative quotes for each theme are presented and are labeled by ethnic group (Ar for Armenian, Ro for Romanian, and Ru for Russian), and gender (W for woman and $\mathrm{M}$ for man), including the number of each respondent.

\section{Need for services: challenges directly linked to immigration}

Among the major immigration struggles that were mentioned are language barriers, economic difficulties, and continuing one's education.

Language difficulties. Knowledge of the host culture language largely determines the ease or difficulty of integration. For people who know the language it is easier to find jobs, to develop social interactions, and become accustomed to the new environment. A lack of knowledge, on the other hand, could hinder the adaptation process and hinder one's success in the new society. While most of the respondents indicate that after a while, they become comfortable with using English, some reported that initial language struggles caused major difficulties during the early years of immigration. Participants also reported that a foreign accent can create difficulties and prompt discrimination. The following comments highlight these principles:

In the beginning it was tough because I didn't speak the language. By the time you get used to dealing with people, it takes a while [Ar, M, 12].

Sometimes people stare at me because of my accent - I don't like that. I think people should accept you the way you are and not say oh you are not American [Ru, W, 21].

When confronted with language barriers many immigrants ask their family or friends for help, especially with translation of documents: 
Yes, being an immigrant impacted me in many ways, Before, I had a language barrier but now I speak English a little. For seven years it was very hard for me and I had to call up my children and nephews to translate [for] me the letters that I received, documents, utility bills, etc. [Ru, W, 2].

Several participants mentioned that learning the language of the host country should be part of a more general preparation for the immigration process that seems to be a significant and necessary step when moving to a different country. In addition to learning the language, this preparatory stage might also include acquiring information about the new society. Unfortunately, there are no systematic programs in immigrant-sending countries to help these families in their process of moving to a different country. Immigration is often a very private process. Several respondents indicated that they wish they had gone through a period of preparation for immigration before arriving to their new country:

I would have wanted to be more prepared and aware when I immigrated to this country. I made the mistake and came here without knowing the language, and made other mistakes as well [Ar, W, 8].

I would want to come to this country more prepared. I wish I came here knowing the language so that I would not have the problems that I have now [Ar, M, 16].

Economic difficulties. Adjusting to a new economic environment takes a considerable effort for members of any cultural group. Because immigrants are at greater risk for poverty, unemployment, and lower income, it is not surprising that the participants spoke of challenges related to their economic circumstances:

My family lives on a fixed income and we cannot afford to buy so many things. Living here for 13 years, I only went on a vacation twice. My rent goes up every two years, the price of food and gas goes up, etc. [Ru, W, 2].

For me, it was very hard. I had struggles and I am still struggling with work, and financially. I deal with it by working hard, taking it day by day, being optimistic [Ar, M, 5]

Another important issue raised in relation to economic situation and employment is the long hours that people are working. Participants frequently expressed dissatisfaction with working too much. When asked what they would change in their lives if they could, many respondents across all three immigrant groups indicated that they would want to have more family time, to spend more time interacting with their spouses and children, and less time at work. This perspective could also indicate a more collectivistic oriented perspective on life than the more individualistic approach characterizing the host country:

I would want to have my salary but fewer of days of work. And the same for my wife. Here, life is on the run, always a lot of work, always feeling tired [Ar, M, 31].

I would have more free time to be able to spend time with the family, to take it easy. I think this would be the most important [Ro, M, 7].

Timing of immigration. Timing of immigration is defined as the life stage at which one migrated. This timing is important because the stage at which a person integrates into the new system will help determine their level of adaptation. Many respondents indicate that they would have preferred to migrate sooner to enhance educational, career, and economic opportunities:

If I would change something in my life, it would have been coming to New York at a younger age. Then I would transfer my diploma and go to college. In my native country, I was a speech pathologist. The main things that bother me are that I could not fully achieve my desired goals $[\mathrm{Ru}, \mathrm{W}, 1]$.

I wish I came here 20 years earlier. Also, I want to learn English and get the profession that I had $[R u, W, 3]$.

I wish to have come to this country earlier [Ar, W, 20].

An important factor related to the timing of immigration is the age at which the person migrates. Age strongly influences the ease with which immigrants are able to adjust to change. The younger people migrate the more able they are to continue their education in the host system, and thereby facilitate adaptation to the new society:

I believe that I have adapted well, better than my parents and better than my brothers because I came to this country at a younger age. I am very proud of myself and where I have gotten myself. 
Challenges related to education and schooling. Acquiring education in the host country was seen by participants as a facilitating factor in the adaptation process. Going to school or continuing one's education is something immigrants expressed longing for, clearly recognizing its value: "I wish I could study again, get good education here in America. It's very important to have good education here. I came to America late, I was 38 and it's very hard for us to study again" [Ar, W, 3].

Being able to transfer educational degrees is an important step in obtaining a job for many immigrants. Not being able to transfer an educational degree or to go to school in the host country prevents many immigrants from being able to find a comparable job as the one they had in their country of origin. As a consequence, it appears that immigrants accept positions that are below their qualification levels and lower paid. Although immigrants with higher education levels have more chances to integrate into the new society, sometimes transferring education credentials or finding a comparable position as the one in the country origin could be difficult and could greatly impact their mental health, as stated by the following participants:

I feel that it was very hard because I didn't know the language. For my parents it was harder because they couldn't go to school and they couldn't do the jobs they did there, here. They settled with different jobs that paid minimum wage, which just paid the rent [Ar, W, 21].

The first two years were very difficult for me. If you did physical work in your country and you come and do it here, then it's ok. When you come to this country, especially if you are educated person, you are used to dealing with educated people it's very hard because you don't know the language and you can't do anything except do physical work. You feel you can do more, your brain is functioning but you can't because you don't have the language. It's very difficult for educated people to come here and not be able to do anything [Ar, W, 23].

\section{Need for services: immigration and family relations}

The participants' perception of the impact of immigration on family functioning, specifically on spousal and parent-child interactions also emerged from the data. The literature on Eastern Europeans presents them as having small but yet very close families (Robila, 2004, 2010).

Marital relationships. Respondents were asked to evaluate the quality of their marital relationship and to indicate the impact of immigration on this interaction. In general, most of the participants reported a good marital relationship, although small day-to-day conflicts were reported. Some participants acknowledge that economic opportunities in the host country contributed to their families having lower levels of conflict:

We have been married for 14 years. I think the relation is very good, calm, without problems. Like in any family, there are small issues, but we don't have problems created by finances, economics, like other young families face. Many times financial problems bring you problems in the marriage. At least here we don't have this issue. I think it is a strong element the fact the day-to-day life issues can be solved easier, and so, at least from this point of view you don't have problems in the family [Ro, M, 18].

In addition, all three Eastern European immigrant groups noted that being married to someone from the same cultural background was perceived as an advantage. The similarity in their background, history of their culture and norms, seemed to facilitate understanding and promote equality in the relationship:

I have been in a relationship for four years. Our relationship is good. We understand each other really well. We are both Armenian, and we have a lot of things in common. Actually, I would not see myself with anybody else but an Armenian, because they know where I come from and all the traditions and it is a lot easier. We have a lot of things in common and we are equal. We have the same experiences from childhood [Ar, W, 32].

I have been married for ten years. The fact that my husband is from the same culture, with the same perspectives on life is a positive thing. I think my relationship with my husband is good, we have known each other for a long period of time, which helps us compensate each other $[\mathrm{Ro}, \mathrm{W}, 1]$. 
Next, most participants reported that immigration influenced their spousal relations, yet only a few interviewees reported major conflicts in the relationship as a result of it:

Yes, we have been married for 18 years. We have been here for four years and the relation is very bad, it is not what it was before. We had many difficulties together and we were not able to solve them together. We try to minimize the conflicts as much as possible [Ro, W, 10].

In some cases participants report that the experience of immigration took both of them through situations that brought their relation to a higher level, with deeper understanding, improved communication and negotiation skills:

I have been married for 21 years. I think immigration made our relationship more powerful, we became closer to each other, because in this country we really need each other, we have to be working hard together. That's the only way to survive in this country because we don't have relatives in this country and it's not the country where we were born [Ar, W, 20].

For many immigrant groups different expectations regarding the gender roles could also be a challenge since many cultures still preserve traditional roles, with men and women having clearly defined and separate responsibilities, while the social expectations in the USA are more egalitarian. Many Eastern European participants reported a mix of traditional with more modern gender roles; however, the traditional views of their original countries seemed to prevail:

Because I lived in a Romanian house, I think it is normal that the wife would cook or clean, even though here it is a little different. So, I am not surprised because I know where he is coming from. I guess if I was from a different culture I would have other expectations, but seeing these things, I am used to live with them, I saw my mother. I don't think it is something good, I do think he should help more especially since the women are working as much as the men, maybe even more [Ro, W, 13].

It's different from what I see in the US and that's because we are Armenian. We have to respect men, that is in our culture. Men is the leader of the family, although, my husband respects my opinion. Each of us has their own role in the family, I am the mother, he takes care of the living. We are very connected with each other. I see families in United States and they are very self-centered - each person has their own world. In our family, it's like a finger on a hand. We cannot be independent, we are free but we are not independent, we all play the same game [Ar, W, 23].

Parenting issues. Eastern European immigrants participating in this study indicated they have very good relationships with their children, loving them very much and being very proud of them. As immigrants, many times parents report feeling stress related to employment issues. As such, the time or energy that they might have spent with their child in meaningful interactions can be siphoned off to solve practical problems. In a few instances, participants shared differences between cultures of the origin and host countries in terms of the expectations for parenting:

Because my parents and I were born in Armenia, there are certain morals that we follow. For example, we have to marry an Armenian and stay with our friends who are Armenian. It is difficult because of the expectations from parents. Every Armenian parent has high expectations for their kids to keep the same traditions and keep the same lifestyle as they had. They feel that is necessary for us to continue and it is difficult when you are in a different country, with different people whose morals are different. I try to live my life the way I want to live it because it is my life and I don't follow every single rule there is [Ar, W, 26].

Living in a different, unknown environment can also increase the anxiety level that parents experience. Several parents indicate feeling that they are not completely aware of the system and are unable to navigate it successfully:

I am not too familiar with the American system. Unlike here, in Russia I knew which were the good schools, professions, and careers. I had a clear picture in my head as to what they had to go through to obtain their career. Me being an immigrant affects me in this area because I feel that I can't advise my children as much as I would want to [Ru, W, 32].

Talking to and listening to their parents, being compliant and respectful, are part of the Eastern European parents' expectations for their children. This value set can contradict

VOL. 7 NO. 42011 INTERNATIONAL JOURNAL OF MIGRATION, HEALTH AND SOCIAL CARE $\mid$ PAGE 189 
some of the widespread parenting values practiced in the host society, such as assertiveness or independence:

We have one son. Our relation is very good, he is compliant, respectful. Sometimes he has a little attitude, but it is ok [M, Ro, 7].

We have two kids. We have no conflicts with our children, they understand that they should listen to their parents $[\mathrm{M}, \mathrm{Ru}, 9]$.

In several instances parents acknowledged the similarities and differences in childrearing practices between country of origin and host society and have indicated their preference for the former:

We have a good, calm relation. My child is educated in the Romanian way, it is far from her the idea of being educated in the American way. Children have different life perspectives here. She is still that child that listens to her parents. We live in a Romanian tradition, I have a very good child [W, Ro, 10].

One of the areas that is greatly impacted by immigration is the relationship with the extended family, which in most cases is left behind in the country of origin. Living closer to their family of origin, however, remains one of the strongest desires that immigrants expressed:

I would like to have all of my family in one country because it is really difficult not seeing your family for long period of time [Ar, W, 27].

\section{Need for services: immigration, adaptation, and quality of life in the host country}

Participants were asked whether they are content with how they adapted to life in the USA and how pleased they are with their quality of life. A common pattern emerged in the responses, namely that it was harder at the beginning but that the things become more manageable later on:

It was hard in the beginning, it took time, it took me two years to get used to the country, to the new culture, everything. I am very happy but I miss my country [Ar, W, 4].

Yes, I adapted after eight years, I got use to this life [Ar, W, 17].

In general, I feel good. After 13 years I adapted myself. In the beginning it was very hard, but now we take everything the way it is. In the beginning I didn't speak the language and I was not able to communicate, but now I can and it's much easier [Ro, W 5].

Participants across all three groups demonstrated a generally positive attitude towards their quality of life, and appreciation of the opportunities provided by immigrating to the USA. However, some also mentioned having mixed feelings about their life:

Yes and No. I am trying. It's not easy. The mindset is different from Russians. Not everyone here can understand me, the jokes are different, many things are different. Americans are more rational, more into calculations, economics, business, money, marketing and stuff like that. Russians are more about the heart and the soul, and love [Ru, W, 20].

Partially yes. Why not 100 per cent - because I am a housewife, I want to be more socially involved with work, education. It's too late for me to pick something normal [Ar, W, 8].

Not 100 per cent but I can say 70 per cent. The biggest problem is the language. When you don't speak clearly you feel strangled, you don't feel good about yourself and that's why I want to continue my education which will help me [Ar, M, 18].

The respondents' ties with their country of origin was also a significant issue relating to quality of life. Visiting their country and maintaining contact with people left behind is crucial to the well-being of many immigrants:

I wish I traveled more to Russia because I kind of lost touch from back home. I haven't been there for three years. I wish I could keep in touch with my family and friends [Ru, M, 35].

I would like to have everything that I have here and take it to my country and be there and live there [Ar, M, 24].

I miss my relatives and friends from Russia. More than half my life I lived there and sometimes I miss their company. Since I came here, I haven't gone back there. I am planning on going in the summer, I am very excited about this [Ru, W, 32]. 
Immigrants indicated that they appreciate their host country and are grateful for the many opportunities in the USA. They are aware that migrating to other areas might have been more challenging, but the openness of the US society towards cultural diversity might have had made the immigration process easier for them. The goal of adaptation is for immigrants to achieve a well-being stage where they feel comfortable in both environments, being able to combine elements from the culture of origin with the ones in the host country: "I think that I have the best of the both worlds. I am happy with health and quality of life" [Ar, M, 34].

An important factor in the adaptation is the presence and access to an immigrant community. Belonging to a community also provides a sense of pride, high self-esteem and courage. Living in an area with a high density of immigrants has been mentioned many times as an advantage:

No, we didn't have too much problems being Armenian immigrants. We are part of the Armenian community and we always had our friends. We were among Armenian people so we didn't have too many problems. It was very hard in the beginning. But now everything is good [Ar, W, 22].

If I could change something I would really want to live in an area with Russians. I want to speak my language, it's important for me, to continue educating friends about my culture. And I would definitely want to continue hanging out with Russians [Ru, M, 18].

You don't really feel so different here in New York because a lot of people are immigrants. I think as long as you know English people are more open to you [Ro, W, 27].

Immigrants often feel grateful to the host country and as such, it is hard for them to ask for services. Moreover, for Eastern European immigrant groups it might be hard to know what services might be available to ask for. Having services that are tailored to their cultural needs might be a way to reduce some of the stigma associated with using these support mechanisms and might encourage migrants to access and use them. Using them earlier in the immigration process could have a protective function in preventing some of the potential challenges associated with migration. As for the other immigrant groups, prevention mechanisms are cheaper and easier to perform than the intervention services.

\section{Discussions and recommendations}

\section{Need for services: challenges of immigration}

Similarly with other groups, Eastern Europeans immigrants experience a series of challenges that they have to overcome during their adaptation process to a new country illustrating their needs for services (Mittal and Hardy, 2005; Wang, 1994). Among them, the most prevalent are language barriers, economic difficulties, and transferring their education credentials or continuing their education in the host country. Most of the immigrants reported having different levels of language barriers, from not knowing English at all to being mocked for their accent. The inability to transfer an educational degree or to go to school in the host country prevents many immigrants from being able to find a comparable job as the one they had before (Hao, 2003; Hao and Ozgur, 2004). As a result, under or unemployment are major issues that contribute to economic difficulties. In terms of the timing of immigration, respondents shared that the sooner they came to the USA the easier it was to adapt and that many wish they had done it even earlier. The age at the immigration is another important factor that influenced the ease with which people were able to adjust to change, being younger or coming younger being perceived as an advantage. Preparation for the immigration was mentioned as crucial by a number of respondents. As expected, it was commonly mentioned that things are harder in the beginning but that in time they become more manageable.

In response to these challenges it is recommended that social support services be developed in migrant sending and receiving countries to provide informational workshops for immigrants which could help them be more prepared for the international migration process. While the focus of this article is on migrants in receiving countries, the need for some of these services in the migrant-sending countries is recognized and it is strongly recommended that these programs be developed. These workshops should provide information about some of the challenges and opportunities of migration, including employment opportunities, 
educational system and degree transferring issues, and/or legislation in the receiving country, etc. (Robila, 2009).

The impact of immigration on families is complex and impacts several levels of family functioning, including relations with extended family, and spousal and parenting subsystems. The impact that geographical distance has on relationships with family of origin is significant and was mentioned by most of the respondents. In terms of marital relations it was reported as an advantage that both partners belonged to the same cultural group, and that this helped them deal with eventual problems. Most of the participants reported that their couple relationship has not been significantly impacted by their immigrant status.

In terms of parent-child relations, sometimes conflicts based on cultural differences and growing up in different environments are reported. As with other groups, Eastern European immigrant children adapt faster to the new country than their parents, requiring the latter to keep up with their children's involvement in the new social, educational, and cultural environment (Baptiste et al., 1997; Portes and Rumbaut, 1996, 2001). For immigrant children, their integration into the school environment has been mentioned as a significant issue (Fuligni, 2003). An important factor in the adaptation is the presence of and access to an immigrant community, and as such living in an area with a high density of immigrants was mentioned many times as an advantage.

It is recommended that social services for immigrants inform individuals and families about the potential impact of migration at the family levels. For example, underling the importance of maintaining active communication channels while handling long-distance relationships with spouses or children would be very helpful. In addition to the economic prosperity that migration brings for a family, it also imposes some risks for the psych-social functioning of family and its members. As a result, specific strategies to prevent the challenges of migration (e.g. children spending long time without their parents) must be developed and implemented.

Participants were asked to report on their adaptation process to the host country and their quality of life in general. While most participants across the three groups indicated positive attitudes toward their life and being appreciative for the opportunities provided by immigrating to the USA, several described mixed feelings about their quality of life. Social services programs could prepare migrants to have realistic expectations regarding this process and could help them understand its different stages. Becoming accustomed to a different country and system takes time and as such, migrants need to be more patient with themselves and with those around them as they go through it.

\section{Barriers in using social services}

Barriers in using social services have been identified for different cultural groups. In different cultures (e.g. Chinese - Wang, 1994; Indian - Mittal and Hardy, 2005) family therapy or counseling is not very popular, with people usually asking for support from extended family and friends before approaching an outside service. However, the immigration process can provoke a disintegration of family support structures, and with fewer supports available the family can really struggle. Therefore, it may become increasingly important for these families to have access to professional support because of the absence of larger family and cultural support. Several barriers in using social services have been identified among Eastern European groups (Folwarski and Smolinski, 2005). Among them are the lack of familiarity with these services due to their reduced presence in their country of origin, and the stigma associate with using these services. Other barriers might be the lack of services targeted specifically to different cultural groups (Laszoffy, 2005). Conducting family therapy with parents and adolescents is important given the fact that adolescents are changing very rapidly. Reflecting on issues regarding adolescence and how international migration impacts them might help both generations understand each other better and adjust to the host environment more effectively.

In many cases, migrating to another country is done not by the whole family system but by individuals or subsystems (only the parents, or only the nuclear family). As such, this 
process is associated with a loss of family and social support. However, having a source of social support might be an effective strategy during the migration, and therefore, accessing professional counseling could be a helpful (and sometimes necessary) outlet.

\section{Strategies to overcome barriers in using services and recommendations for therapy}

Hardy and Laszloffy (2002, p. 570) recommend using a multicultural perspective (MCP) while conducting couple therapy with immigrants. One of the assumptions of MCP is considering culture as a broad-based multidimensional concept, "illuminating how a person can simultaneously occupy two seemingly divergent roles, such as privileged and subjugated". This perspective is very important while working with Eastern European immigrants. Owing to the fact that they are Caucasian, frequently they are considered as being privileged while some of their challenges may be overshadowed. Often, their needs as immigrants are not known and acknowledged as those of other immigrants groups, and as such the number of support services targeting their needs is extremely limited. Using this multidimensional view of culture would allow scholars and practitioners to understand that Eastern European immigrants have needs similar in nature with those of other cultural groups.

This multidimensional view of culture also explains the differences that may exist among members of the same cultural group (Hardy and Laszloffy, 2002). This is a very important issue for Eastern European immigrants, because since they are all coming from a relatively small geographical region, many times they are perceived as being the same, while complex cultural differences exist among them, such as language, historical or religious background.

Being familiar with the cultural values and norms of one's clients is a necessary step in achieving a successful therapy outcome. As Baptiste et al. (1997) write about effective family therapy with English Caribbean immigrant families in the USA, they recommend therapists become knowledgeable about these families' cultural values and traditions in order to create a respectful atmosphere where families can feel valued. Similarly, in the case of Eastern European immigrants, it would be advisable for clinicians to be aware of some of the socio-historical and cultural background of these groups. For example, due to the history of this region, specifically communism and distrust of outsiders, it would be useful to underline the confidentiality of the therapeutic environment, to explain in detail the therapeutic process and to allow some time for client to develop trust. Another useful strategy might be the de-stigmatization of the therapy or counseling services, which would again involve explaining the process, normalizing it, indicating that in this country many people are using it and benefiting from it. As part of this, it might be useful to underline the fact that family therapy or counseling is not used by people who are "crazy" but by people who at some point in their life might experience difficulties and using some social support might help them handle their problems more effectively.

Recommendations regarding the availability of programs are presented on multiple levels. At the level of society, social services programs should be developed to target different cultural groups. A second level is the immigrant communities which through their advocacy strategies should strive to develop support programs for their members. The size of the immigrant community is an important factor since larger groups usually have more resources and capacities to develop these types of organizations and services for their cultural groups (e.g. Russians vs Bulgarians). However, there is a need for these types of services for smaller groups as well. Developing such community-based agencies is recommended as a way to ease the integration of these groups into society. At the immigrant family or individual level the recommendation is for people to accessing these programs and resources in order to receive the support needed in solving some of their problems. Although the focus of this article is on providing recommendations for therapy and practice with immigrants in the USA, developing immigrant support programs in immigrant-sending countries that would help with the preparations for this process is highly recommended.

The limitations of the study include the fact that this it is based on a study conducted with only three Eastern European groups and the snowball effect of the sampling. However, given the limited information about these groups the study fills an important gap in the literature on 
conducting therapy with different cultural groups. The recommendations for future research include conducting multiple-methods and multiple-informants studies with other Eastern European immigrant groups and developing further therapy strategies tailored specifically to different cultural groups.

Since international migrants are part of family systems, a family perspective is strongly recommended to be used in developing policies regulating international migration (Robila, 2009). As such, as a base of this policymaking effort, the research on international migrant families (instead of only on individual migrants) becomes increasingly important as does the process of examining the effectiveness of international migration policies on all family members in providing feedback for potential needed policy revisions.

\section{References}

Alba, R. and Nee, V. (2003), Remaking the American Mainstream: Assimilation and Contemporary Immigration, Harvard University Press, Cambridge, MA.

Bakalian, A. (1993), Armenian-Americans: From Being to Feeling Armenian, Transaction Publishers, New Brunswick, NJ.

Baptiste, D.A., Hardy, K. and Lewis, L. (1997), "Family therapy with English Caribbean immigrant families in the United States: issues of emigration, immigration, culture and race", Contemporary Family Therapy, Vol. 19, pp. 337-59.

Berg, I.K. and Jaya, A. (2007), "Different and same: family therapy with Asian American families", Journal of Marital and Family Therapy, Vol. 19, pp. 31-8.

Bodrug-Lungu, V. (2004), "Families in Moldova", in Robila, M. (Ed.), Families in Eastern Europe, Elsevier, San Diego, CA, pp. 173-87.

Buchwald, D., Klacsanzsky, G. and Mason, S. (1993), "Psychiatric disorders among recently arrived Eastern European seen through a US refugee counseling service", International Journal of Social Psychiatry, Vol. 39, pp. 221-7.

Charmaz, K. (1983), "The grounded theory method: an explication and interpretation", in Emerson, R.M. (Ed.), Contemporary Field Research, Waveland, Prospect Heights, IL, pp. 109-26.

Coatsworth, J.D., Maldonado-Molina, M., Pantin, H. and Szapocznik, J. (2005), "A person centered and ecological investigation of acculturation strategies in Hispanic immigrant youth", Journal of Community Psychology, Vol. 33, pp. 157-74.

Falicov, C. (1988), "Learning to think culturally", in Liddle, H.A., Breunlin, D.C. and Schwartz, R.C. (Eds), Handbook of Family Therapy and Supervision, Gilford Press, New York, NY, pp. 335-57.

Falicov, C. and Karrer, B. (1984), "Therapeutic strategies for Mexican-American families", International Journal of Family Therapy, Vol. 6, pp. 16-30.

Folwarski, J. and Smolinski, J. (2005), "Polish families", in McGoldrick, M., Giordano, J. and Garcia Preto, N. (Eds), Ethnicity and Family Therapy, 3rd ed., Gilford Press, New York, NY, pp. 741-56.

Fuligni, A.J. (2003), "The adaptation of children from immigrant families", International Society for the Study of Behavioral Development Newsletter, Vol. 44, pp. 9-11.

Hao, L. (2003), "Private support and public assistance for immigrant families", Journal of Marriage and the Family, Vol. 65, pp. 36-52.

Hao, L. and Ozgur, C. (2004), "The complexity of returns to education: race, nativity, and country and field of degree", paper presented at the 2004 Annual Meetings of the American Sociological Association, San Francisco, CA, August.

Hardy, K. and Laszloffy, T. (2002), "Couple therapy using a multicultural perspective", in Gurman, A.S. and Jacobson, N.S. (Eds), Clinical Handbook of Couple Therapy, 3rd ed., Guilford Press, New York, NY, pp. 569-93.

International Organization for Migration (2007), "Migration management", Moldova, available at: www. iom.md/ 
Kinzie, D.J., Leung, P., Bui, A., Ben, R., Keopraseuth, K.O., Riley, C., Fleck, J. and Ades, M. (1998), "Group therapy with Southeast Asian refugees", Community Mental Health Journal, Vol. 24, pp. 157-66.

Krestan, J. and Gazarik, R.M. (2005), "Czech and Slovak families", in McGoldrick, M., Giordano, J. and Garcia-Preto, N. (Eds), Ethnicity and Family Therapy, 3rd ed., Gilford Press, New York, NY, pp. 724-41.

Krupinski, J., Stoller, A. and Wallace, L. (1973), "Psychiatric disorders in East European refugees now in Australia", Social Science \& Medicine, Vol. 7, pp. 31-49.

Laszoffy, T.A. (2005), "Hungarian families", in McGoldrick, M., Giordano, J. and Garcia-Preto, N. (Eds), Ethnicity and Family Therapy, 3rd ed., Gilford Press, New York, NY, pp. 586-95.

Leon Siantz, M.L. (1997), "Factors that impact developmental outcomes of immigrant children", in Booth, A., Crouter, A.C. and Landale, N.S. (Eds), Immigration and the Family: Research and Policy on US Immigrants, Lawrence Erlbaum Associates, Hillsdale, NJ, pp. 149-65.

Levenbach, D. and Lewak, B. (1995), "Immigration: going home or going to pieces", Contemporary Family Therapy, Vol. 17, pp. 379-94.

McGoldrick, M., Giordano, J. and Garcia-Preto, N. (2005), Ethnicity and Family Therapy, Gilford Press, New York, NY

Manoogian, M.M., Walker, A.J. and Richards, L.N. (2007), "Gender, genocides and ethnicity: the legacies of older Armenian mothers", Journal of Family Issues, Vol. 28, pp. 567-89.

Massey, D.S., Arango, J., Hugo, G., Kouaouci, A., Pellegrino, A. and Taylor, J.E. (1998), Worlds on Motion: Understanding International Migration at the End of the Millennium, Claredon Press, Oxford.

Migration Watch UK (2009), "Future migration flows from Eastern Europe", European Union, Vol. 4.8, pp. 1-5.

Mittal, M. and Hardy, K.V. (2005), "A re-examination of the current status and future of family therapy in India", Contemporary Family Therapy: An International Journal, Vol. 27, pp. 285-300.

Newhouse, R. (2005), "Russian Jewish Families", in McGoldrick, M., Giordano, J. and Garcia Preto, N. (Eds), Ethnicity and Family Therapy, 3rd ed., Gilford Press, New York, NY, pp. 701-11.

Okoomian, J. (2002), "Becoming white: contested history, Armenian American women, and racialized bodies", MELUS, Vol. 27, pp. 213-37.

Papazian, D. (2000), "Armenians in America", Journal of Eastern Christian Studies, Vol. 52, pp. 311-47.

Parra-Cardona, R., Córdova, J.D., Holtrop, K. and Villa, F.A. (2008), "Shared ancestry, evolving stories: similar and contrasting life experiences described by foreign born and US born Latino parents", Family Processes, Vol. 47, pp. 157-72.

Phinney, J.S., Romero, I., Nava, M. and Huang, D. (2001), "The role of language, parents, and peers in ethnic identity among adolescents in immigrant families", Journal of Youth and Adolescence, Vol. 30, pp. 135-53.

Portes, A. and Hao, L. (2002), "The price of uniformity: language, family and personality adjustment in the immigrant second generation”, Ethnic and Racial Studies, Vol. 25, pp. 889-912.

Portes, A. and Rumbaut, R.G. (1996), Immigrant America: A Portrait, University of California Press, Berkeley, CA.

Portes, A. and Rumbaut, R.G. (2001), Legacies: The Story of Immigrant Second Generation, Russell Sage, New York, NY.

Robila, M. (Ed.) (2004), Families in Eastern Europe, Elsevier, San Diego, CA.

Robila, M. (2007), "Eastern European immigrants in the United States: a socio-demographic profile", The Social Science Journal, Vol. 44, pp. 113-25.

Robila, M. (2008), "Characteristics of Eastern European immigration in the United States", Journal of Comparative Family Studies, Vol. 39, pp. 545-57.

Robila, M. (2009), "Integrating a family perspective in international migration policy", Invited paper for the Eighth Coordination Meeting on International Migration, Population Division, Department of Economic and Social Affairs, United Nations, New York, NY.

Robila, M. (2010), Eastern European Immigrant Families, Routledge, New York, NY. 
Rumbaut, R. (1994), "The crucible within: ethnic identity, self-esteem, and segmented assimilation among children of immigrants", International Migration Review, Vol. 28, pp. 748-94.

Schmidley, A.D. (2003), Foreign Born population in United States. Current Population Reports, US Census Bureau, Washington, DC, pp. 20-539.

Strauss, A. and Corbin, J. (1990), The Basics of Qualitative Research, Sage, Newbury Park, CA.

Szapocznik, J., Scopetta, M.A. and King, O.E. (1978), "Theory and practice in matching treatment to the special characteristics and problems of Cuban immigrants", Journal of Community Psychology, Vol. 6 , pp. 112-222.

Urban Institute (2003), "The new neighbors: a user's guide to data on immigrants in US communities", US Census 2001. US Government, Urban Institute, Washington, DC.

US Department of Homeland Security (2008), Legal Immigrants to the United States.

Wang, L. (1994), "Marriage and family therapy with people from China", Contemporary Family Therapy, Vol. 16 No. 1, pp. 25-37.

Yip, T. and Fuligni, A.J. (2002), "Daily variations in ethnic identity, ethnic behaviors, and psychological well-being among American adolescents of Chinese descent", Child Development, Vol. 73, pp. 1557-72.

Young, R.F., Bukoff, A., Waller, J.B. Jr and Blount, S.B. (1987), "Health status, health problems and practices among refugees from the Middle East, Eastern Europe and Southeast Asia", International Migration Review, Vol. 21, pp. 761-83.

Zeng, Z. and Xie, Y. (2004), "Asian-Americans' earnings disadvantage reexamined: the role of place of education", American Journal of Sociology, Vol. 109, pp. 1075-108.

\section{Further reading}

Falicov, C. (1983), Cultural Perspectives in Family Therapy, Aspen, Rockville, MD.

Falicov, C. (2000), Latino Families in Therapy: A Guide to Multicultural Practice, Gilford Press, New York, NY.

Fuligni, A.J., Tseng, V. and Lam, M. (1999), "Attitudes toward family obligation among American adolescents with Asian, Latin, and European backgrounds", Child Development, Vol. 70, pp. 1030-44.

Hao, L. (2004), "Wealth of immigrant and native-born Americans", International Migration Review, Vol. 38, pp. 518-46.

Karakashian, M. and Poghosyan, G. (2003), "Armenian migration and a diaspora: a way of life", in Loeb Adler, L., Kleiner, R.J. and Gielen, U.P. (Eds), Migration: Immigration and Emigration in International Perspective, Praeger Publishers, Westport, CT, pp. 225-43.

Suárez-Orozco, C. and Suárez-Orozco, M. (2001), Children of Immigration, Harvard University Press, Cambridge, MA.

Zhou, M. (1997), "Growing up American: the challenge confronting immigrant children and children of immigrants", Annual Review of Sociology, Vol. 23, pp. 63-95.

\section{Corresponding author}

Mihaela Robila can be contacted at: mihaela.robila@qc.cuny.edu

To purchase reprints of this article please e-mail: reprints@emeraldinsight.com

Or visit our web site for further details: www.emeraldinsight.com/reprints 
Reproduced with permission of the copyright owner. Further reproduction prohibited without permission. 